\title{
Level of Knowledge About Coronary Artery Disease is Poor Among Bangladeshi Hospitalized Patient Following Acute Coronary Syndrome
}

\author{
MD. MOTLABUR RAHMAN, ${ }^{1}$ M.A. SATTAR SARKER, ${ }^{2}$ TANIA MAHBUB, ${ }^{3}$ SHAHANA KHANAM, ${ }^{4}$ \\ NAHIDA ZAFRIN, ${ }^{5}$ M.A. AZHAR ${ }^{6}$
}

\begin{abstract}
:
Back ground: Coronary artery disease (CAD) is a major risk of death worldwide. Level of education about this important health problem is poor in our general population. Aims of this study was to find out simple knowledge about coronary disease, and to find the knowledge about risk factors, symptoms, complications and knowledge about prevention of coronary disease among the hospitalized patient who admitted to SSMS and Mitford Hospital and diagnosed as patients of Acute Coronary Syndrome (ACS).
\end{abstract}

Method: A pre tested questionnaire regarding assessment of level of knowledge about CAD was used to studied of the patients was admitted to SSMC and Mitford Hospital with the diagnosis of acute coronary syndrome during the period April 2009 to October 2009.

Result: Our study suggests that there is a lack of awareness among a sampled Bangladeshi population regarding CAD and its modifiable risk factors. We found that the low level of knowledge in the majority of patients, the rural and less educated patients had a lower level of knowledge.

Conclusion: Our cardiac patients have poor knowledge regarding their disease; improvement of knowledge is needed through much education to prevent CAD.

Key words: Coronary artery disease, Knowledge, Acute coronary syndrome.

\section{Introduction:}

The heart is the human body's hardest working organ. Throughout life it continuously pumps blood enriched with oxygen and vital nutrients through a network of arteries to all parts of the body's tissues. Coronary heart disease (CHD) is a major health burden and cost to healthcare. ${ }^{1}$ Acute coronary syndrome (ACS), encompassing a range of disorders from unstable angina through non ST elevation to ST elevation myocardial infarction, is a leading cause of death in the world in both developed and developing countries $^{2}$. The South Asian countries like India, Pakistan, Bangladesh, Sri Lanka, and Nepal account for about a quarter of the world's population and contribute the highest proportion of the burden of cardiovascular diseases as

1. Consultant, Department of Medicine, DMCH, Dhaka

2. Registrar, Dept of Medicine, SSMC and Mitford Hospital, Dhaka

3. Medical officer, Dept. of Nephrology, DCH, Dhaka

4. Assistant Prof., Dept of Microbiology, M. H. Samorita Medical College, Dhaka

5. Medical officer, Dept. of Family Planning, SSMC and Mitford Hospital, Dhaka

6. Professor and Head, Dept of Medicine, SSMC and Mitford Hospital, Dhaka

Correspondence: Dr. Md, Motlabur Rahman. Consultant, Department of Medicine, Dhaka Medical College Hospital. Emailrahmanmotlabur@gmail.com compared with any other region globally. ${ }^{2,3}$ However, there is no published data for prevalence or incidence of CAD in Bangladesh. World Health Organization has predicted, by 2020 up to three quarters of death in the developing countries would result from non-communicable diseases and $\mathrm{CAD}$ will top of the list of the killers.

"Barriers to seeking appropriate care quickly are both cognitive and emotional." If patients do not know the symptoms of acute myocardial infarction (heart attack) and other acute coronary syndromes - including nausea and pain in the jaw, chest or left arm - they will not seek treatment for them. If they do not perceive themselves to be at risk for heart attack, they will look for another explanation when they experience these symptoms. ${ }^{4}$ Nearly half of patients with a history of heart disease have poor knowledge about the symptoms of a heart attack and do not perceive themselves to have an elevated cardiovascular risk. Individuals with heart disease have five to seven times the risk of having a heart attack or dying as the general population.

\section{Subjects \& Methods:}

The study was a cross sectional study conducted in Sir Salimullah Medical College \& Mitford Hospital during the period from April 2009 to October 2009. Keeping compliance with Helsinki Declaration for Medical Research Involving 
Human Subjects 1964, all the subjects selected for study were informed orally and in writing about the study design, objectives and right for the participant to withdraw from the project at any time, for any reason, what so ever. The study population was the patients undergoing coronary heart disease admitted to SSMC and Mitford Hospital following acute coronary syndromes (Diagnosed by symptom, ECG criteria and enzyme level) irrespective of sex. A total of 95 subjects meeting the inclusion criteria (Patient admit to hospital for chest pain and diagnosed as ACS, Both sex, Age above 18 yrs) was selected consecutively.

A structured questionnaire was developed containing multiple questions, covering different area regarding knowledge about coronary artery disease and its risk factors, perception of CAD, different modalities of treatment, dietary factors and clinical situation when patient should seek medical attention. The socio-demographic variables included in the proposed study were age, sex, religion, residence, level of education and monthly income, assessment of clinical parameters, history about known risk factors, emergency service related variables, were set for knowledge assessment of the patients. A structured questionnaire was formed which included all the variables of interest. The questionnaire was finalized following pre-testing and taking necessary feedbacks from cardiologist and the guide. Form was pretested and necessary modifications were done.

The level of knowledge and practice status was measured using Likert Scale Score. Score '1' was assigned for each correct answer and score ' 0 ' for each wrong answer. As there were more than one question in assessing respondents' level of knowledge and practice, combined scores ('70' for 70 questions) were used to measure respondents' perspective and practice about coronary artery diseases. The levels of knowledge and practice were measured on a $0-4$ Likert Scale, where 0 means 'grossly dissatisfactory' and 4 'highly satisfactory' with 'poor' 1 , 'more or less satisfactory' 2, and 'satisfactory' 3 in between them. First the level of knowledge and practice were assessed for responses against each question. Then all these scores were added together to find an overall level of knowledge and practice. Data were collected from the respondents by a self-administered questionnaire. Collected data were processed and analyzed with the help of software SPSS (Statistical Package for Social Sciences) version 11.5. Statistical analyses were done with help of descriptive statistics, Chi-square (c2) Probability Test. Level of significance for all analyses was set at 0.05 and p-value $<0.05$ was considered significant.

\section{Result:}

In our study, the mean age was $57.2 \pm 8.4$ years and youngest and oldest patients were 29 and 82 years respectively. Approximately two third $(65.3 \%)$ of patients were urban residents and $34.7 \%$ rural residents. Nearly half $(48.5 \%)$ of the patients were primary level educated, $32.6 \%$ secondary, $8.4 \%$ graduate, $6.3 \%$ higher secondary and $4.3 \%$ was post graduate. knowledge about the risk factors, $26.3 \%$ of patients mentioned effect of smoking, $15.8 \%$ diabetes, $14.7 \%$ hypertension, $9.5 \%$ family history of CAD, $4.2 \%$ obesity, $2.1 \%$ heredity. Diet, stress and others causes each comprised of $3.2 \%$ of patients, based on this categorization of Likert Scale, $5.3 \%$ of the respondents had highly satisfactory level of knowledge, $6.3 \%$ satisfactory and $12.6 \%$ more or less satisfactory and $22.1 \%$ had poorly satisfactory knowledge. About 54\% of the respondents' answer was grossly dissatisfactory. Grossly dissatisfactory knowledge was significantly higher in rural respondents compared in urban respondents $(78.8 \%$ vs. $40.3 \%, \mathrm{p}=0.006)$.

Majority $(90.5 \%)$ of the patients learn about coronary artery disease from hospital, $89.5 \%$ from doctors, $4.2 \%$ from friends and $5.3 \%$ from media.

Table-I

Respondents' answer about risk factors of developing $C A D(n=95)$

\begin{tabular}{lcc}
\hline Factors developing CAD & Frequency & Percentage \\
\hline Effect of smoking & 25 & 26.3 \\
Diabetes & 15 & 15.8 \\
Hypertension & 14 & 14.7 \\
Obesity & 04 & 4.2 \\
Stress & 03 & 3.2 \\
Heredity & 02 & 2.1 \\
Diet & 03 & 3.2 \\
Family history of CAD & 09 & 9.5 \\
Others & 03 & 3.2 \\
\hline
\end{tabular}

* Total may not correspond to $100 \%$ for multiple responses

Table-II

Respondents' answer perception about symptoms of CAD $(n=95)$

\begin{tabular}{lcc}
\hline Symptoms & Frequency & Percentage \\
\hline Chest pain & 42 & 46.2 \\
Difficulty breathing or & 17 & 18.0 \\
shortness of breath & & \\
Sweating & 13 & 13.6 \\
Nausea or vomiting & 02 & 2.1 \\
Fear of impending death & 01 & 1.1 \\
\hline
\end{tabular}

* Total may not correspond to $100 \%$ for multiple responses 
Table-III

Comparison of knowledge between urban and rural population

\begin{tabular}{lccr}
\hline Level of knowledge & \multicolumn{2}{c}{ Group } & p-value \\
\cline { 2 - 3 } & Urban(n=68) & Rural(n=27) & \\
\hline Grossly dissatisfactory & $25(40.3)$ & $26(78.8)$ & \\
Poorly satisfactory & $16(25.8)$ & $5(15.2)$ & \\
More or less satisfactory & $10(16.1)$ & $2(6.1)$ & 0.006 \\
Satisfactory & $7(11.3)$ & 00 & \\
Highly satisfactory & $4(6.5)$ & 00 & \\
\hline
\end{tabular}

\#Chi-square $\left(\mathrm{c}^{2}\right)$ Test was employed to analyzed the data. Figures in the parenthesis denote corresponding percentage

Table-IV

Distribution of respondents' answer how they learn about $C A D(n=95)$

\begin{tabular}{lcc}
\hline Respondents answer & Frequency & Percentage \\
\hline Hospital & 86 & 90.5 \\
Doctor/Nurse & 85 & 89.5 \\
Friend & 04 & 4.2 \\
Media & 05 & 5.3 \\
\hline
\end{tabular}

* Total may not correspond to $100 \%$ for multiple responses

Table-V

Respondents' distribution by level of knowledge about $C A D(n=95)$

\begin{tabular}{lcc}
\hline Level of knowledge & Frequency & Percentage \\
\hline Grossly dissatisfactory & 51 & 53.7 \\
Poorly satisfactory & 21 & 22.1 \\
More or less satisfactory & 12 & 12.6 \\
Satisfactory & 06 & 6.3 \\
Highly satisfactory & 05 & 5.323 \\
\hline
\end{tabular}

\section{Discussion:}

Based on this categorization of Likert Scale, $5.3 \%$ of the respondents had highly satisfactory level of knowledge, $6.3 \%$ satisfactory and $12.6 \%$ more or less satisfactory and $22.1 \%$ had poorly satisfactory knowledge. About $54 \%$ of the respondents' answer was grossly dissatisfactory. Grossly dissatisfactory knowledge was significantly higher in rural respondents compared in urban respondents $(78.8 \%$ vs. $40.3 \%, \mathrm{p}=0.006$ ). Robert ${ }^{12}$ reported that nearly half of patients with a history of heart disease have poor knowledge about the symptoms of a heart attack and do not perceive themselves to have an elevated cardiovascular risk and 44 percent of the patients had a low knowledge level which was contrast with the present study. Assiri ${ }^{13}$ also demonstrated that the level of knowledge in the majority of patients was poor, the older and the less educated patients had a lower level of knowledge. The patients showed improved level of knowledge during their stay in the hospital. Majority (90.5\%) of the patients learn about coronary artery disease from hospital, $89.5 \%$ from doctors, $4.2 \%$ from friends and 5.3\% from media.

Among the risk factors of $\mathrm{CAD}, 26.3 \%$ of patients mentioned effect of smoking, $15.8 \%$ diabetes, $14.7 \%$ hypertension, $9.5 \%$ family history of CAD, $4.2 \%$ obesity, $2.1 \%$ heredity. Diet, stress and others causes each comprised of $3.2 \%$ of patients. Hlatky ${ }^{14}$ described that patients with coronary disease were more likely to smoke cigarettes, and to have diabetes and hypertension and a history of prior myocardial infarction. Sharma ${ }^{15}$ et al. also reported in his article $42 \%$ had chest pain. Hypertension ( $91 \%$ of all patients), $39 \%(n=50)$ were diabetic. Lahiri ${ }^{16}$ also found that hypertension was the most common risk factor [46 (54.7\%)], followed by diabetes [29 (34.5\%)]; 17 (20.2\%) were smokers, 15 (17.8\%) were dyslipidemic and $3(3.5 \%)$ had a family history of premature coronary artery disease.

During hospital admission over $46 \%$ of patients complained of chest pain, $18 \%$ difficulty breathing or shortness of breath, $13.6 \%$ sweating, $2.1 \%$ nausea or vomiting and $1.1 \%$ fear of impending death. Kane ${ }^{17}$ demonstrated that $64 \%$ of patients with heart disease have chest pain, $13 \%$ difficulty breathing, $11 \%$ sweating which was nearly consistent with our study.

\section{Conclusion:}

Coronary Artery Disease is a major killer worldwide. Public awareness of risk factors for coronary heart disease (CAD) is essential, but no previous measures of it exist in Bangladesh, where it is on the rise and the incidence of $\mathrm{MI}$ is dramatically increasing. Our study suggests that there is a lack of awareness among a sampled Bangladeshi population regarding modifiable risk factors of CAD. Level of education about this important health problem is unknown in our local population. We found the level of knowledge in the majority of patients was poor; the rural and less educated patients had a lower level of knowledge.

\section{Recommendations:}

1. Education on risk factors imparted through health programs is necessary to create awareness and thus prevent CAD.

2. Regular antismoking campaigns should be held for school and college students

3. Men's lifestyles put them at particular risk of CHD; therefore there is a clear need for more effective health promotion that encourages men to change their risk behaviors. 


\section{Conflict of Interest : None}

\section{References:}

1. Australian Institute of Health and Welfare (AIHW). Heart, Stroke and Vascular Diseases_-Australian Facts 2004. Canberra: AIHW; 2004.

2. Reddy KS. Cardiovascular diseases in non-Western countries. N Engl J Med 2004; 350:2438- 40.

3. Avezum A, Makdisse $M$ \& Spencer F... GRACE Investigators. Impact of age on management and outcome of acute coronary syndrome: observations from the Global Registry of Acute Coronary Events (GRACE). Am Heart J. 2005; 149:67-73.

4. Robert A \& Phillips MD. Many patients with heart disease have poor knowledge of heart attack symptoms. Arch Intern Med 2008; 168(10):1049-1054.

5. Pal J, Sarkar N, Mukherjee JD, Talukdar A, Karmakar PS, Chatterjee $\mathrm{M}$ et al. Prevalence of Metabolic Syndrome in Coronary Artery Disease. Indian Heart J 2005; 57:381-425.

6. Sheifer SE, Gresh BJ, Weinfurt KP, Oetgern J, Breall JA \& Schulman KA. Time to Presentation with Acute Myocardial Infarction in the Elderly. Circulation 2000, 102:1651- 63.

7. Almas A, Hameed A, Sultan FAT. Knowledge of Coronary Artery Disease (CAD) risk factors and Coronary Intervention among University Student. JPMA 2008;58:553.

8. Zalman S \& Agus MD. Many With Coronary Disease Continue to Smoke Despite Physicians' Advice. Am Heart J 2005; 150(2): 221- 6 .

9. Strike PC, Magid K, Brydon L, Edwards S, McEwan JR, \& Steptoe A. Exaggerated Platelet and Hemodynamic Reactivity to Mental Stress in Men With Coronary Artery Disease. Psychosomatic Medicine 2004; 66:492-500.

10. Reddy KS \& Yusuf S. Emerging epidemic of cardiovascular disease in developing countries. Circulation 1998; 97: 596-601.

11. Khan MA, Jafary FH, Faruqui AM, Rasool SI, Hatcher J, Chaturvedi $\mathrm{N}$ et al. High prevalence of lack of knowledge of symptoms of acute myocardial infarction in Pakistan and its contribution to delayed presentationto the hospital. BMC Public Health 2007; 7:284.

12. Robert A. Many patients with heart disease have poor knowledge of heart attack symptoms. JAMA 2008; 145(3):1234-6.

13. Assiri AS. Knowledge about coronary artery disease among patients admitted to Aseer Central Hospital with acute coronary syndrome. West Afr J Med. 2003; 22(4):314-7.

14. Hlatky MA, Lam LC, Lee KL, Clapp-Channing NE, Williams RB, Pryor DB et al. Job Strain and the Prevalence and Outcome of Coronary Artery Disease. Circulation. 1995; 92:327- 33 .

15. Sharma R, Pellerin D, Gaze DC, Gregson H, Streather CP, Paul $\mathrm{O}$ et al. Dobutamine stress echocardiography and the resting but not exercise electrocardiograph predicts severe coronary artery disease in renal transplant candidates. Nephrology Dialysis Transplantation 2005; 20(10): 2207-14.

16. Lahiri S, Sethi KK, Jain R, Sawhney JPS, Chopra VK, Dhawan $\mathrm{S}$ et al. Coronary Ectasia: prevalence, Clinical and Angiographic Charecteristics. The Lancet 1996; 23(5):175-9.

17. Kane FJ Jr, Strohlein J \& Harper RG. Noncardiac chest pain in patients with heart disease. South Med J 199; 84:847-52. 